Article

\title{
The microRNA-455 Null Mouse Has Memory Deficit and Increased Anxiety, Targeting Key Genes Involved in Alzheimer's Disease
}

\author{
Tracey E. Swingler ${ }^{1}$, Lingzi Niu ${ }^{1}$, Matthew G. Pontifex ${ }^{2}$, David Vauzour ${ }^{2, *,+} \mathbb{D}$ and Ian M. Clark ${ }^{1, *,+} \mathbb{D}$ \\ 1 School of Biological Sciences, University of East Anglia, Norwich NR4 7TJ, UK; t.swingler@uea.ac.uk (T.E.S.); \\ 1.niu@uea.ac.uk (L.N.) \\ 2 Norwich Medical School, University of East Anglia, Norwich NR4 7TJ, UK; m.pontifex@uea.ac.uk \\ * Correspondence: d.vauzour@uea.ac.uk (D.V.); i.clark@uea.ac.uk (I.M.C.); Tel.: +44-1603-592760 (I.M.C.) \\ + These authors contributed equally to this work.
}

check for

updates

Citation: Swingler, T.E.; Niu, L.; Pontifex, M.G.; Vauzour, D.; Clark, I.M. The microRNA-455 Null Mouse Has Memory Deficit and Increased Anxiety, Targeting Key Genes Involved in Alzheimer's Disease. Int. J. Mol. Sci. 2022, 23, 554. https:// doi.org/10.3390/ijms23010554

Academic Editors: Masaru Tanaka and Lydia Giménez-Llort

Received: 10 November 2021 Accepted: 30 December 2021 Published: 5 January 2022

Publisher's Note: MDPI stays neutral with regard to jurisdictional claims in published maps and institutional affiliations.

Copyright: (C) 2022 by the authors. Licensee MDPI, Basel, Switzerland. This article is an open access article distributed under the terms and conditions of the Creative Commons Attribution (CC BY) license (https:// creativecommons.org/licenses/by/ $4.0 /)$.

\begin{abstract}
The complete molecular mechanisms underlying the pathophysiology of Alzheimer's disease (AD) remain to be elucidated. Recently, microRNA-455-3p has been identified as a circulating biomarker of early $\mathrm{AD}$, with increased expression in post-mortem brain tissue of $\mathrm{AD}$ patients. MicroRNA-455-3p also directly targets and down-regulates APP, with the overexpression of miR455-3p suppressing its toxic effects. Here, we show that miR-455-3p expression decreases with age in the brains of wild-type mice. We generated a miR-455 null mouse utilising CRISPR-Cas9 to explore its function further. Loss of miR-455 resulted in increased weight gain, potentially indicative of metabolic disturbances. Furthermore, performance on the novel object recognition task diminished significantly in miR-455 null mice $(p=0.004)$, indicating deficits in recognition memory. A slight increase in anxiety was also captured on the open field test. BACE1 and TAU were identified as new direct targets for miR-455-3p, with overexpression of miR-455-3p leading to a reduction in the expression of $A P P, B A C E 1$ and TAU in neuroblastoma cells. In the hippocampus of miR-455 null mice at 14 months of age, the levels of protein for APP, BACE1 and TAU were all increased. Such findings reinforce the involvement of miR-455 in AD progression and demonstrate its action on cognitive performance.
\end{abstract}

Keywords: Alzheimer's disease; microRNA; miR-455; knockout; APP; TAU; BACE1; novel object recognition; memory; anxiety

\section{Introduction}

There are approximately 50 million people worldwide currently living with dementia, and this figure is predicted to rise considerably over the next three decades $[1,2]$. Alzheimer's disease (AD) is the most common form of dementia accounting for approximately two thirds of dementia cases [3]. The progressive and debilitating nature of the disease make it a major cause of disability and mortality in later life, with no disease modifying treatment currently available [4]. The classic hallmarks of AD consist of cognitive decline and the presence of amyloid plaques and neurofibrillary tangles (NFT) [5]. According to the amyloid hypothesis [6], pathological conditions lead to altered/increased metabolism of the amyloid precursor protein (APP), under the actions of the $\beta$-secretase, BACE1 and $\gamma$-secretases, presenilin 1 and 2 (PSEN1 and PSEN2). APP cleavage leads to the production and aggregation of the amyloid $\beta$ peptide $(A \beta)$ and the formation of amyloid plaques, resulting in neurotoxicity and eventual death of the neuron $[7,8]$. On the other hand, the TAU (microtubule-associated protein tau) hypothesis [9] emphasises the importance of aberrant TAU phosphorylation and subsequent NFT formation, which undermines microtubule integrity resulting in structural and transport deficits in the neurons $[10,11]$. Further processes such as neuroinflammation have also been proposed to 
explain the mechanistic basis of the disease, with proinflammatory cytokines elevated in the brains and serum of AD patients [12,13]. Mitochondrial dysfunction and oxidative stress (increased production of reactive oxygen species) are also seen [14]. AD is likely attributable to a combination of processes, adding to its complexity, and as a result, the overall molecular pathogenesis remains poorly understood.

Small non-coding RNAs known as microRNAs (miRNAs) are important regulators of gene expression in human cells [15]. MicroRNAs are transcribed as primary transcripts (pri-miRNA) and processed to short stem-loop structures (pre-miRNA) in the nucleus. The pre-miRNA is then processed by the ribonuclease, DICER, forming two complementary short RNA molecules one of which (the guide strand) is integrated into the RNA-induced silencing complex (RISC), the other of which (the passenger strand) is degraded. After integration into RISC, miRNAs base pair with their complementary mRNA targets, usually in the $3^{\prime}$ UTR [16] to degrade mRNA or repress translation. A number of miRNAs have been shown to have roles in regulating $\mathrm{AD}$ associated proteins, targeting processes that contribute to $\beta$-amyloid production (e.g., BACE1 and APP), TAU phosphorylation and mitochondrial dysfunction (reviewed in $[17,18]$ ). MicroRNAs and their target genes act in regulatory networks which are disrupted in disease [19]. Key miRNAs may act as biomarkers of pathology or even be targets for therapeutic intervention [18].

MicroRNA-455 is genomically located in an intron of the collagen type XXVII alpha 1 chain gene (COL27A1) and has previously been implicated in cartilage biology [20], with roles in the TGF $\beta$ signalling pathway [20,21]. A number of studies have shown miR455 to be dysregulated in a variety of pathologies including cancers and cardiovascular disease [22]. Recently, microRNA-455-3p was identified as a circulating biomarker in early $\mathrm{AD}$ [23] with levels of miR-455-3p upregulated in patients with mild cognitive impairment (MCI) and AD. Furthermore, miR-455-3p expression is increased in the post-mortem brain tissue and cells derived from AD patients when compared to healthy controls, [24]. MicroRNA-455-3p has also been shown to directly target and down-regulate APP, with the overexpression of miR-455 suppressing APP toxicity [25] providing a mechanistic explanation for its increased expression in AD.

In order to determine the function of miR-455 in vivo, we utilised a miR-455 null mouse, constructed using CrispR/Cas9. Behavioural tests of cognition and in vitro molecular analyses were employed to further delineate miR-455 function within the brain.

\section{Results}

\subsection{MicroRNA-455-3p Expression Decreases with Age and Is Absent in the Null Mouse Model}

The miR-455 null mouse was made by the Genome Editing Unit, University of Manchester, UK. Microinjection of one-day single cell C57/BL6 mouse embryos used in vitro transcribed sgRNA and recombinant Cas9 protein (https://sites.manchester.ac.uk/genomeediting-unit/publications/, accessed on 15 October 2021). Sequencing of genomic DNA from founder mice revealed a number of deletions within the targeted pre-miR-455 locus. One of these was identified as a 35-base deletion, removing part of both miR-455-5p and miR-455-3p mature sequences, as well as the intervening hairpin sequence (Figure 1A). This mouse was bred with a wild-type C57/BL6 and heterozygote offspring bred together to give homozygous null mice; these were maintained alongside wild-type littermates as parallel colonies. Deletion was confirmed by sequencing of genomic DNA.

Expression of miR-455 was absent in all tissues tested, with Figure 1B showing expression in the brain at 3 months of age. At 14 months of age, miR-455 null mice were significantly larger than the wild-type comparators (Figure 1C). Expression of miR-455-3p in the brain decreased across 3 weeks to 12 months of age in wild-type mice ( $p=0.04$, Figure 1D). 
A

5' CTCCCTGGTGTGAGCGTATGTGCCTTTGGACTACATCGTGAACGCAGCACCATGCAGTCCACGGGCATATACACTTGCCTCA $3^{\circ}$ 5' CTCCCTGGTGTGAGCGIATGTGCC--...- CACGGGCATATACACTTGCCTCA 3'

B

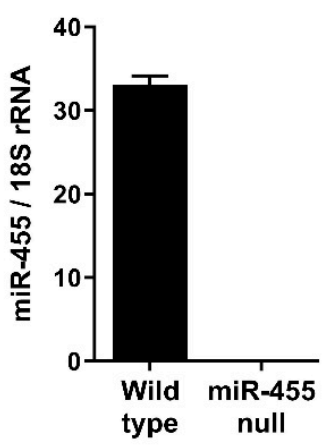

D

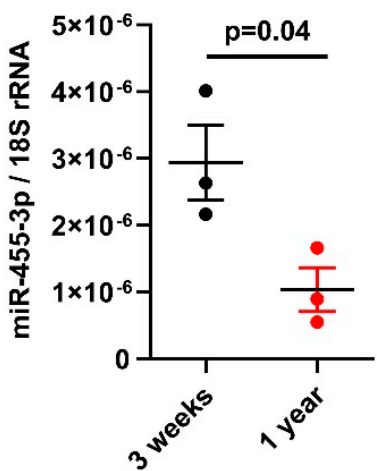

C

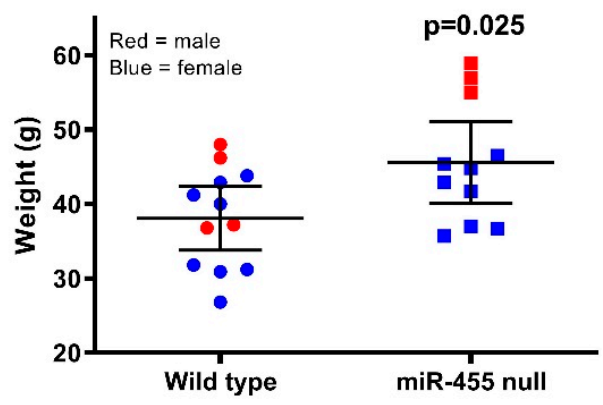

Figure 1. The miR-455 null mouse and the expression of miR-455-3p across age. (A) Deletion of miR455 in mice. Sequencing of miR-455 null founder mouse shows a 35-base deletion, deleting both miR455-5p and miR-455-3p mature sequences, as well as the intervening hairpin sequence. (B) Expression of miR-455-3p in 3-month-old mouse brain tissue. RNA was extracted from brain tissue and qRT-PCR performed; the miR-455 null mouse shows complete loss of miR-455-3p expression. (C) MiR-455 null mice show increased weight gain with age. Mice were weighed each month and showed that at 14 months of age, miR-455 null mice $(n=13)$ were significantly heavier than wild-type litter mates $(n=11)$. (D) MiR-455 expression decreases with age in wild-type mice. RNA was extracted from brain tissue at 3 weeks and 12 months of age and qRT-PCR performed $(n=3)$. Mean \pm SEM.

\subsection{Recognition Memory Is Impaired in miR-455 Null Mice}

We compared wild-type with miR-455 null mice at 14 months of age in both novel object recognition and the open field test. In object recognition, miR-455 null mice showed significantly impaired recognition memory compared to wild-type controls $(p=0.004$, Figure 2A). In the open field test, miR-455 null mice displayed a slight increase in anxiety overall spending less time in the centre of the arena $(p=0.09$, Figure $2 \mathrm{~B})$, with no alteration in motor function (Figure 2C).

\subsection{BACE1 and TAU Are Direct Targets of miR-455-3p}

$A P P$ has previously been identified as a direct target for miR-455-3p [25]. Here, we also identified $B A C E 1$ and TAU as other targets. Expression of luciferase controlled by the $3^{\prime}$ UTR of either the BACE1 or TAU genes shows that miR-455-3p reduces this expression and that this is rescued by mutation of the miR-455-3p seed site in each UTR (Figure 3A,B). Expression of $A P P, B A C E 1$ and $T A U$ were all decreased after overexpression of miR-455-3p in SH SY5Y neuroblastoma cells (Figure 3C,D). 
A

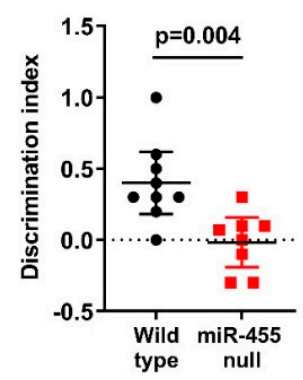

B

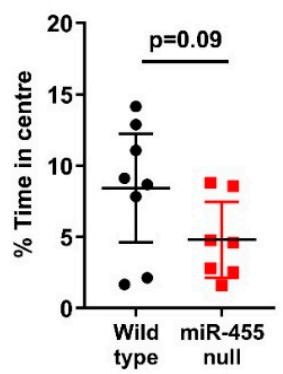

C

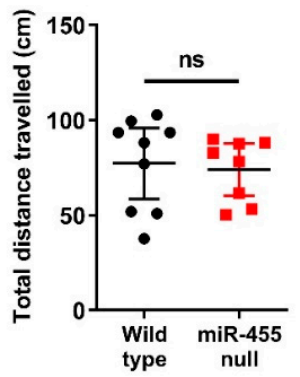

Figure 2. Behavioural studies comparing the miR-455 null mouse vs. wild-type. (A) 14-month-old miR-455 null $(n=9)$ mice and wild type mice $(n=8)$ were tested for recognition memory using the novel object recognition test (NOR); miR-455 null mice have significant recognition memory deficit as indicated by a decreased discrimination index. (B) Anxiety behaviour was tested using the open field test. MiR-455 null mice display an increase in anxiety with (C) no difference in overall locomotion. Bars show the mean \pm SEM.

A

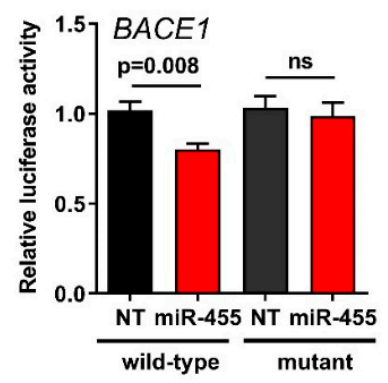

C

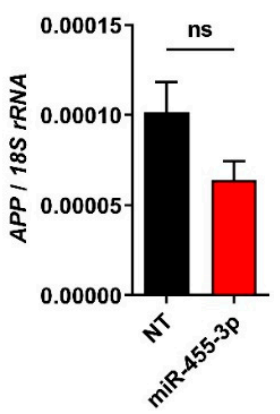

B

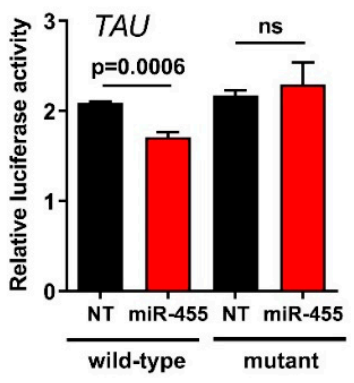

E

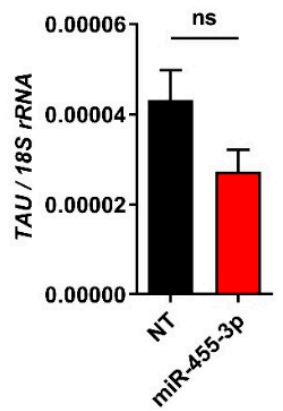

Figure 3. miR-455-3p directly targets BACE1 and TAU. Cells (DF1 fibroblasts) were transfected with the $3^{\prime}$-untranslated region of BACE1 (A), TAU (B) or the corresponding seed site mutants, cloned into pmiR-GLO \pm non-targeting control (NT) or miR-455-3p mimic (miR-455) and incubated for $24 \mathrm{~h}$. Relative light units were normalized to Renilla activity. Bars show the mean $\pm \mathrm{SEM} ; n=4$. SH SY5Y neuroblastoma cells were transfected with miR-455-3p mimic or non-targeting control (NT) for $48 \mathrm{~h}$ prior to measurement of APP (C), BACE1 (D) and TAU (E) by qRT-PCR. Bars show the mean \pm SEM, $n=3$.

\subsection{The Levels of APP, BACE1 and TAU Proteins Are Increased in miR-455 Null Mouse Hippocampus}

Both RNA and proteins were extracted from the hippocampus of wild-type vs. miR455 null mice at 14 months of age. The level of both App and Bace1 gene expression were not significantly different between groups (Figure 4A,B), although Tau expression was significantly increased in the miR-455 null mice $(p=0.046$, Figure $4 \mathrm{C})$. However, Western blot showed a significant increase in APP $(p=0.0013)$ and BACE1 $(p=0.0447)$ 
protein levels in miR-455 null mice compared to wild-type (Figure 4D,E). Although it did not reach significance, protein levels of TAU were higher in miR-455 null vs. wild type mice (Figure 4F).

A

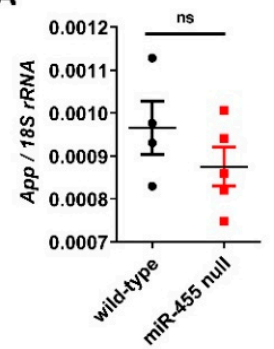

D
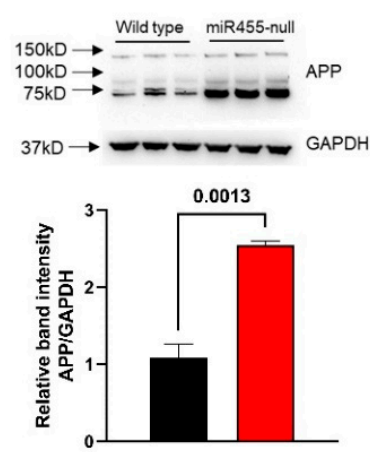

B

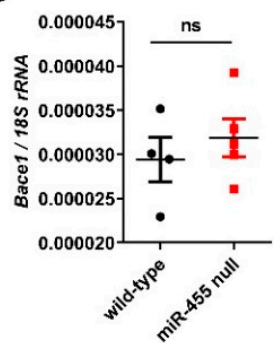

E
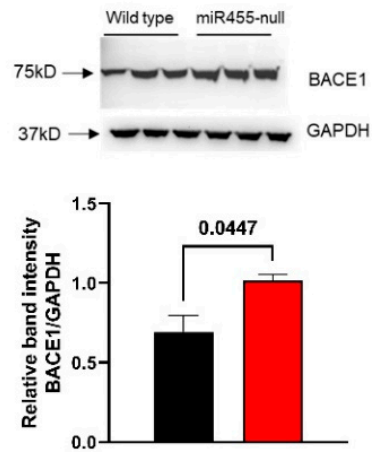

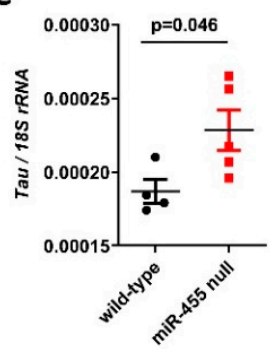

F

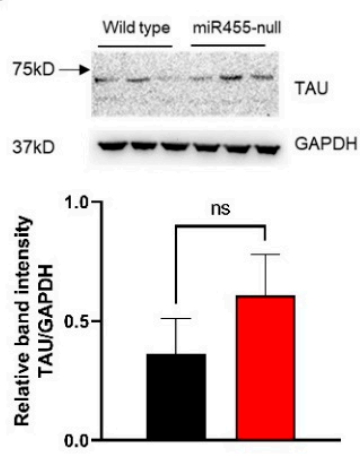

Figure 4. Expression of App, Bace1 and Tau in the mouse hippocampus. RNA and proteins were extracted from the hippocampus of wild-type vs. miR-455 null mice at 14 months of age. Levels of App, Bace1 and Tau were measured by qRT-PCR (A-C) and Western blot and densitometric analyses (D-F). Results are presented as mean \pm SEM, $n=4$ wild type and $n=5$ miR- 455 null for RNA levels and $n=3$ for both wild type and miR-455 null for protein levels.

\section{Discussion}

MicroRNA-455 has been described as a circulating biomarker of AD and is increased in the brains of AD patients [22-24]. Additionally, miR-455-3p has known roles in APP processing and abrogates the impact of mutant APP in vitro [25]. After revealing a decrease of miR-455-3p expression in ageing wild type mice, CrispR-Cas 9 microinjection was used to create a miR-455 null mouse in order to determine its function in vivo. Behavioural assessment revealed deficits in recognition memory and increased anxiety in null mice. $B A C E 1$ and TAU genes were shown to be direct targets for miR-455-3p. The use of homologous recombination was precluded because of the proximity of miR-455 to the downstream exon of the COL27A1 gene. The deletion of 35 bases across the $5 p$ and $3 p$ sequences within the pre-miRNA hairpin was sufficient to prevent processing and no mature miR-455 was detected. A second deletion in founder mice was also bred forwards and no difference in phenotype of these mice has been detected (data not shown).

Expression of miR-455-3p decreased with age in the mouse brain across 12 months (Figure 1D). The expression of all microRNAs in mouse brain with ageing has previously been examined using RNA-Seq analysis [26,27], however $n$ numbers were small and the read number of miR-455 using this technique was too small for analyses. The expression of a number of microRNAs both increase and decrease in the brain significantly across age. Roles for miRNAs in the brain are diverse, including modulation of synaptic plasticity, cognition, inflammation, neuroprotection, lipid metabolism and mitochondrial function [28,29]. MicroRNA-455 null mice were significantly heavier than their wild-type counterparts at 14 months of age (Figure 1C) and this divergence starts around 6 months of age (Supplementary Figure S1). Although the role of obesity as a risk factor for AD remains 
uncertain [30,31] alterations in energy metabolism are now considered a prerequisite in AD progression [32-35].

Loss of miR-455 influenced recognition memory with null mice performing significantly worse on the novel object recognition task compared to the wild-type controls (Figure 2A). A slight increase in anxiety, was also noted Figure 2B). Correlation analyses of NOR discrimination index with open field percentage time in centre or travelled distance showed no significant interaction indicating that anxiety did not impact on the NOR output (see Supplementary Figure S2). Several microRNAs implicated in AD have also been shown to impact these outcomes, including miR-9 [36], miR-124 [37], miR-101 [38], miR-153 [39], miR-132/212 [40] and miR-181a [41,42].

MicroRNA-455 has been shown to directly target and downregulate APP [25], suppressing its toxic effects. We extended this to demonstrate that both human BACE1 and TAU are also direct targets for miR-455-3p (Figure 3A,B) with APP, BACE1 and TAU expression suppressed by the overexpression of miR-455-3p (Figure 3C-E). In the miR-455 null mouse hippocampus, the protein levels of APP, BACE1 and TAU are all increased, though for APP and BACE1, this does not correlate with mRNA levels. In part this may be due to a small $\mathrm{n}$ number, but post-transcriptional mechanisms may also contribute. This clearly has potential to add to the pathology of AD via the amyloid or Tau axis. Although APP, $B A C E 1$ and TAU have been implicated in impaired recognition memory [43-46] we have not demonstrated that this is the mechanism of action of miR-455.

In addition to our current findings, we have preliminary evidence to suggest miR-455 may also target components of the core clock machinery and likely impacts the upon circadian rhythm (Swingler et al., unpublished observations). This may provide another link to AD [47].

The main limitations to the current study are the future need to compare the miR455 null mouse with a transgenic mouse overexpressing miR-455-3p. A greater suite of behavioural studies across age would identify the age of onset for the phenotype and enable targeted molecular studies to address mechanism further.

Altogether, the findings here suggest that miR-455-3p is neuroprotective, with loss of miR-455 across age leading to increased AD related gene expression and subsequent cognitive deficits. However, the knowledge that miR-455-3p [22] is increased in AD complicates this narrative. We hypothesize that the $\mathrm{AD}$ associated increase may represent a futile attempt to control pathology and is ultimately overwhelmed. Increasing research is warranted to further detail the interaction of miR-455 with brain physiology and pathology.

\section{Materials and Methods}

\subsection{MiR-455 Null Mouse}

MiR-455 mice were made using CRISR-Cas9 by the Transgenic Unit, University of Manchester (https://sites.manchester.ac.uk/genome-editing-unit/, accessed 15 October 2021). Mice were maintained in a controlled environment under the Home Office Code of Practice $\left(21+/-2{ }^{\circ} \mathrm{C}\right.$, humidity $55+/-10 \%, 12$-h light/dark cycles (lights on at $07: 00 \mathrm{~h}$ and off at 19:00 h), HEPA filtered air) and fed ad libitum on a standard chow diet (RM3-P; Special Diet Services, Essex, UK) for the duration of the experiments.

\subsection{Behavioural Assessment}

Behavioural tests were performed as previously described $[48,49]$ on mice aged to 14 months old. Objects and arenas were cleaned with $70 \%(v / v)$ ethanol in between each trial. To evaluate anxiety behaviour and locomotion open field test was performed. Briefly, mice were placed in a house built $50 \mathrm{~cm} \times 50 \mathrm{~cm} \times 50 \mathrm{~cm}$ apparatus illuminated with low lux (100 lux) lighting and could move freely. Recognition memory was assessed using novel object recognition task (NOR) [50]. The open field test (Day 1) was used as the acclimatisation phase for the NOR experiment. On day 2, mice were placed into the same arena containing two identical objects and allowed to explore for $15 \mathrm{~min}$. The mice were returned to their cages for a period of $1 \mathrm{~h}$. Animals were again placed into their respective 
arenas for a final time, the arena contained one original object and one novel object, and the mouse was free to explore either for a 10-min period. Mice were included in the analysis that explored objects for a period of 10 secs or greater. Videos were analysed for the full the 10 -min period and time spent with each object was determined. Discrimination index (DI) was calculated using the following formula $\mathrm{DI}=(\mathrm{TN}-\mathrm{TF}) /(\mathrm{TN}+\mathrm{TF})$ where $\mathrm{TN}$ is time exploring the novel object and TF is time spent exploring the familiar object.

\subsection{Overexpression of $m i R-455-3 p$}

SH SY5Y neuroblastoma cells were plated in 96-well plate wells at a density of $7 \times 10^{4}$ cells $/ \mathrm{mL}$ in $100 \mu \mathrm{L}$ and grown to $80-90 \%$ confluence. MicroRNA-455-3p mimic ( $\left.50 \mathrm{nM}\right)$ or non-targeting control $(50 \mathrm{nM})$ were transfected in using Lipofectamine 3000 (Thermo Fisher Scientific, Paisley, UK), according to manufacturer's instructions for $48 \mathrm{~h}$. Total RNA was extracted using Trizol (ThermoFisher Scientific, Paisley, UK) according to the manufacturer's instructions).

\subsection{RNA and Protein Extraction from Mouse Brains}

Mice were euthanized and the brains were immediately removed and dissected for the cerebral cortex, and hippocampus. Brain tissue was snap frozen and ground in liquid nitrogen. Total RNA was extracted from $20 \mathrm{mg}$ tissue using Trizol (ThermoFisher Scientific, Paisley, UK) according to the manufacturer's instructions. Protein was extracted using NE-PER reagents (ThermoFisher Scientific, Paisley, UK) according to the manufacturer's instructions.

\subsection{Quantitative Real-Time PCR}

Complementary DNA was synthesized from 300 ng RNA using SuperScript II reverse transcriptase (Invitrogen, Paisley, UK) and either random hexamers or miRNA-specific primers (Applied Biosystems, Paisley, UK) according to the manufacturer's instructions. 18S rRNA was used as the housekeeping gene. Complementary DNA was stored at $-20^{\circ} \mathrm{C}$. The relative quantitation of gene expression was performed using an ABI Prism 7700 Sequence Detection System (Applied Biosystems, Paisley, UK), following the manufacturer's protocol.

\subsection{Luciferase Assay}

The $3^{\prime} \mathrm{UTR}$ of mRNAs containing the predicted binding site of miR-455-3p were subcloned into pmirGLO (Promega, Chilworth, UK), using QuikChange II XL site-directed mutagenesis kit (Agilent, Stockport, UK) to introduce mutations. Constructs were sequence verified (Source Bioscience, Nottingham, UK). DF1 fibroblast cells were seeded into 96-well plate wells at $5 \times 10^{4}$ cells $/ \mathrm{mL}$ in $100 \mu \mathrm{L}$ medium overnight and transiently transfected with $100 \mathrm{ng}$ reporter plasmid, 30nM miR-455-3p mimic (Qiagen, Manchester, UK) or non-targeting control (AllStars, Qiagen, Manchester, UK) using Lipofectamine 3000 (Thermo Fisher Scientific, Paisley, UK), according to manufacturer's instructions for $24 \mathrm{~h}$. Cell lysates were assayed for luciferase using the Dual Luciferase Reporter Assay Kit (Promega, Chilworth, UK), read with an EnVision 2103 Multilabel plate reader (Perkin Elmer, Beaconsfield, UK). Relative luciferase activity was the ratio of firefly luciferase to Renilla luciferase activity

\subsection{Western Blot}

Samples were separated on reducing SDS-PAGE, transferred to PVDF membrane and probed overnight at $4{ }^{\circ} \mathrm{C}$. Antibodies against APP (A87840), BACE1 (A80396) and TAU (A98434) were all from antibodies.com (Cambridge, UK). The antibody against GAPDH (\#2118) was from Cell Signalling Technology (London, UK). All antibodies were used at recommended concentrations and were detected using HRP-conjugated secondary antibodies (DAKO, Stockport, UK), visualised using Pierce ${ }^{\mathrm{TM}}$ ECL Western Blotting Substrate (ThermoFisher Scientific, Paisley, UK), and imaged by ChemiDoc ${ }^{\mathrm{TM}} \mathrm{MP}$ Imaging System (BioRad, Watford, UK). 


\subsection{Statistical Analysis}

Data were normally distributed and therefore analysed using Student's $t$-test to compare between two samples, or one-way ANOVA with post hoc Tukey's test to compare between multiple samples using GraphPad Prism version 6. The details of all statistical analyses are shown in Supplementary Table S1.

Supplementary Materials: The supporting information can be downloaded at: https:/ /www.mdpi. com/article/10.3390/ijms23010554/s1.

Author Contributions: T.E.S. and L.N. performed the research and analysed the data with advice from D.V., M.G.P., T.E.S. and I.M.C. All contributed to research direction. All authors wrote and edited the manuscript. All authors have read and agreed to the published version of the manuscript.

Funding: T.E.S. was funded by a Dunhill Medical Trust Programme grant (number R476/0516); L.N. was funded by Action Arthritis and Funds for Women Graduates (number GA-00842).

Institutional Review Board Statement: All experimental procedures and protocols used in this study were reviewed and approved by the Animal Welfare and Ethical Review Body (AWERB) and were conducted within the provisions of the U.K. Home Office Animals (Scientific Procedures) Act 1986 (PF50C7689).

Informed Consent Statement: Not applicable.

Data Availability Statement: Data will be made available upon request.

Acknowledgments: We would like to thank staff in the Disease Modelling Unit for their generous help with these studies.

Conflicts of Interest: The authors declare no conflict of interest.

\section{References}

1. Available online: https://www.who.int/news-room/fact-sheets/detail/dementia (accessed on 15 October 2021).

2. Prince, M.; Bryce, R.; Albanese, E.; Wimo, A.; Ribeiro, W.; Ferri, C.P. The global prevalence of dementia: A systematic review and metaanalysis. Alzheimers Dement. 2013, 9, 63-75.e2. [CrossRef]

3. Kumar, A.; Sidhu, J.; Goyal, A.; Tsao, J.W. Alzheimer Disease; StatPearls: Treasure Island, FL, USA, 2021.

4. Picanco, L.C.D.S.; Ozela, P.F.; Brito, M.d.F.d.B.; Pinheiro, A.A.; Padilha, E.C.; Braga, F.S.; da Silva, C.H.T.d.P.; Dos Santos, C.B.R.; Rosa, J.M.C.; da Silva Hage-Melim, L.I. Alzheimer's Disease: A Review from the Pathophysiology to Diagnosis, New Perspectives for Pharmacological Treatment. Curr. Med. Chem. 2018, 25, 3141-3159. [CrossRef] [PubMed]

5. DeTure, M.A.; Dickson, D.W. The neuropathological diagnosis of Alzheimer's disease. Mol. Neurodegener. 2019, 14, 32. [CrossRef] [PubMed]

6. Selkoe, D.J.; Hardy, J. The amyloid hypothesis of Alzheimer's disease at 25 years. EMBO Mol. Med. 2016, 8, 595-608. [CrossRef]

7. Dawkins, E.; Small, D.H. Insights into the physiological function of the $\beta$-amyloid precursor protein: Beyond Alzheimer's disease. J. Neurochem. 2014, 129, 756-769. [CrossRef]

8. Haass, C.; Kaether, C.; Thinakaran, G.; Sisodia, S. Trafficking and Proteolytic Processing of APP. Cold Spring Harb. Perspect. Med. 2012, 2, a006270. [CrossRef] [PubMed]

9. Arnsten, A.F.T.; Datta, D.; Del Tredici, K.; Braak, H. Hypothesis: Tau pathology is an initiating factor in sporadic Alzheimer's disease. Alzheimer's Dement. 2020, 17, 115-124. [CrossRef] [PubMed]

10. Ballard, C.; Gauthier, S.; Corbett, A.; Brayne, C.; Aarsland, D.; Jones, E. Alzheimer's disease. Lancet 2011, 377, 1019-1031. [CrossRef]

11. Kametani, F.; Hasegawa, M. Reconsideration of Amyloid Hypothesis and Tau Hypothesis in Alzheimer's Disease. Front. Neurosci. 2018, 12, 25. [CrossRef]

12. Calsolaro, V.; Edison, P. Neuroinflammation in Alzheimer's disease: Current evidence and future directions. Alzheimers Dement. 2016, 12, 719-732. [CrossRef] [PubMed]

13. Tanaka, M.; Toldi, J.; Vécsei, L. Exploring the Etiological Links behind Neurodegenerative Diseases: Inflammatory Cytokines and Bioactive Kynurenines. Int. J. Mol. Sci. 2020, 21, 2431. [CrossRef]

14. Catanesi, M.; d'Angelo, M.; Tupone, M.G.; Benedetti, E.; Giordano, A.; Castelli, V.; Cimini, A. MicroRNAs Dysregulation and Mitochondrial Dysfunction in Neurodegenerative Diseases. Int. J. Mol. Sci. 2020, 21, 5986. [CrossRef]

15. O'Brien, J.; Hayder, H.; Zayed, Y.; Peng, C. Overview of MicroRNA Biogenesis, Mechanisms of Actions, and Circulation. Front. Endocrinol. 2018, 9, 402. [CrossRef]

16. Winter, J.; Jung, S.; Keller, S.; Gregory, R.I.; Diederichs, S. Many roads to maturity: MicroRNA biogenesis pathways and their regulation. Nat. Cell Biol. 2009, 11, 228-234. [CrossRef] [PubMed] 
17. Wang, M.; Qin, L.; Tang, B. MicroRNAs in Alzheimer's Disease. Front. Genet. 2019, 10, 153. [CrossRef] [PubMed]

18. Angelucci, F.; Cechova, K.; Valis, M.; Kuca, K.; Zhang, B.; Hort, J. MicroRNAs in Alzheimer's Disease: Diagnostic Markers or Therapeutic Agents? Front. Pharmacol. 2019, 10, 665. [CrossRef]

19. Brito, L.M.; Ribeiro-dos-Santos, Â.; Vidal, A.F.; de Araújo, G.S. Differential Expression and miRNA-Gene Interactions in Early and Late Mild Cognitive Impairment. Biology 2020, 9, 251. [CrossRef]

20. Swingler, T.E.; Wheeler, G.; Carmont, V.; Elliott, H.R.; Barter, M.J.; Abu-Elmagd, M.; Donell, S.T.; Boot-Handford, R.P.; Hajihosseini, M.K.; Munsterberg, A.; et al. The expression and function of microRNAs in chondrogenesis and osteoarthritis. Arthritis Rheum. 2012, 64, 1909-1919. [CrossRef] [PubMed]

21. Hu, S.; Zhao, X.; Mao, G.; Zhang, Z.; Wen, X.; Zhang, C.; Liao, W.; Zhang, Z. MicroRNA-455-3p promotes TGF- $\beta$ signaling and inhibits osteoarthritis development by directly targeting PAK2. Exp. Mol. Med. 2019, 51, 1-13. [CrossRef] [PubMed]

22. Kumar, S.; Reddy, P.H. A New Discovery of MicroRNA-455-3p in Alzheimer's Disease. J. Alzheimers Dis. 2019, 72, S117-S130. [CrossRef] [PubMed]

23. Kumar, S.; Vijayan, M.; Reddy, P.H. MicroRNA-455-3p as a potential peripheral biomarker for Alzheimer's disease. Hum. Mol. Genet. 2017, 26, 3808-3822. [CrossRef] [PubMed]

24. Kumar, S.; Reddy, P.H. MicroRNA-455-3p as a Potential Biomarker for Alzheimer's Disease: An Update. Front. Aging Neurosci. 2018, 10, 41. [CrossRef]

25. Kumar, S.; Reddy, A.P.; Yin, X.; Reddy, P.H. Novel MicroRNA-455-3p and its protective effects against abnormal APP processing and amyloid beta toxicity in Alzheimer's disease. Biochim. Biophys. Acta Mol. Basis Dis. 2019, 1865, 2428-2440. [CrossRef] [PubMed]

26. Inukai, S.; de Lencastre, A.; Turner, M.; Slack, F. Novel microRNAs differentially expressed during aging in the mouse brain. PLoS ONE 2012, 7, e40028. [CrossRef]

27. Mohammed, C.P.; Rhee, H.; Phee, B.K.; Kim, K.; Kim, H.J.; Lee, H.; Park, J.H.; Jung, J.H.; Kim, J.Y.; Kim, H.C.; et al. miR-204 downregulates EphB2 in aging mouse hippocampal neurons. Aging Cell 2016, 15, 380-388. [CrossRef]

28. Mohammed, C.P.D.; Park, J.S.; Nam, H.G.; Kim, K. MicroRNAs in brain aging. Mech. Ageing Dev. 2017, 168, 3-9. [CrossRef]

29. Cao, D.-D.; Li, L.; Chan, W.-Y. MicroRNAs: Key Regulators in the Central Nervous System and Their Implication in Neurological Diseases. Int. J. Mol. Sci. 2016, 17, 842. [CrossRef]

30. Fitzpatrick, A.L.; Kuller, L.H.; Lopez, O.L.; Diehr, P.; O'Meara, E.S.; Longstreth, W.T., Jr.; Luchsinger, J.A. Midlife and late-life obesity and the risk of dementia: Cardiovascular health study. Arch. Neurol. 2009, 66, 336-342. [CrossRef]

31. Profenno, L.A.; Porsteinsson, A.P.; Faraone, S.V. Meta-analysis of Alzheimer's disease risk with obesity, diabetes, and related disorders. Biol. Psychiatry 2010, 67, 505-512. [CrossRef]

32. Atti, A.R.; Valente, S.; Iodice, A.; Caramella, I.; Ferrari, B.; Albert, U.; Mandelli, L.; De Ronchi, D. Metabolic Syndrome, Mild Cognitive Impairment, and Dementia: A Meta-Analysis of Longitudinal Studies. Am. J. Geriatr. Psychiatry 2019, $27,625-637$. [CrossRef]

33. Borshchev, Y.Y.; Uspensky, Y.P.; Galagudza, M.M. Pathogenetic pathways of cognitive dysfunction and dementia in metabolic syndrome. Life Sci. 2019, 237, 116932. [CrossRef] [PubMed]

34. Tolppanen, A.M.; Solomon, A.; Soininen, H.; Kivipelto, M. Midlife vascular risk factors and Alzheimer's disease: Evidence from epidemiological studies. J. Alzheimers Dis. 2012, 32, 531-540. [CrossRef]

35. Cunnane, S.C.; Trushina, E.; Morland, C.; Prigione, A.; Casadesus, G.; Andrews, Z.B.; Beal, M.F.; Bergersen, L.H.; Brinton, R.D.; de la Monte, S.; et al. Brain energy rescue: An emerging therapeutic concept for neurodegenerative disorders of ageing. Nat. Rev. Drug Discov. 2020, 19, 609-633. [CrossRef] [PubMed]

36. Sim, S.E.; Lim, C.S.; Kim, J.I.; Seo, D.; Chun, H.; Yu, N.K.; Lee, J.; Kang, S.J.; Ko, H.G.; Choi, J.H.; et al. The Brain-Enriched MicroRNA miR-9-3p Regulates Synaptic Plasticity and Memory. J. Neurosci. 2016, 36, 8641-8652. [CrossRef] [PubMed]

37. Michely, J.; Kraft, S.; Muller, U. miR-12 and miR-124 contribute to defined early phases of long-lasting and transient memory. Sci. Rep. 2017, 7, 7910. [CrossRef]

38. Lippi, G.; Fernandes, C.C.; Ewell, L.A.; John, D.; Romoli, B.; Curia, G.; Taylor, S.R.; Frady, E.P.; Jensen, A.B.; Liu, J.C.; et al. MicroRNA-101 Regulates Multiple Developmental Programs to Constrain Excitation in Adult Neural Networks. Neuron 2016, 92, 1337-1351. [CrossRef]

39. Mathew, R.S.; Tatarakis, A.; Rudenko, A.; Johnson-Venkatesh, E.M.; Yang, Y.J.; Murphy, E.A.; Todd, T.P.; Schepers, S.T.; Siuti, N.; Martorell, A.J.; et al. A microRNA negative feedback loop downregulates vesicle transport and inhibits fear memory. Elife 2016, 5, 463. [CrossRef] [PubMed]

40. Hansen, K.F.; Sakamoto, K.; Aten, S.; Snider, K.H.; Loeser, J.; Hesse, A.M.; Page, C.E.; Pelz, C.; Arthur, J.S.; Impey, S.; et al. Targeted deletion of miR-132/-212 impairs memory and alters the hippocampal transcriptome. Learn. Mem. 2016, 23, 61-71. [CrossRef]

41. Griffiths, B.B.; Ouyang, Y.B.; Xu, L.; Sun, X.; Giffard, R.G.; Stary, C.M. Postinjury Inhibition of miR-181a Promotes Restoration of Hippocampal CA1 Neurons after Transient Forebrain Ischemia in Rats. eNeuro 2019, 6. [CrossRef]

42. Zhang, S.F.; Chen, J.C.; Zhang, J.; Xu, J.G. miR-181a involves in the hippocampus-dependent memory formation via targeting PRKAA1. Sci. Rep. 2017, 7, 8480. [CrossRef]

43. Biundo, F.; Del Prete, D.; Zhang, H.; Arancio, O.; D'Adamio, L. A role for tau in learning, memory and synaptic plasticity. Sci. Rep. 2018, 8, 3184. [CrossRef] 
44. Evans, C.E.; Thomas, R.S.; Freeman, T.J.; Hvoslef-Eide, M.; Good, M.A.; Kidd, E.J. Selective reduction of APP-BACE1 activity improves memory via NMDA-NR2B receptor-mediated mechanisms in aged PDAPP mice. Neurobiol. Aging 2019, 75, 136-149. [CrossRef] [PubMed]

45. Fukumoto, H.; Takahashi, H.; Tarui, N.; Matsui, J.; Tomita, T.; Hirode, M.; Sagayama, M.; Maeda, R.; Kawamoto, M.; Hirai, K.; et al. A noncompetitive BACE1 inhibitor TAK-070 ameliorates Abeta pathology and behavioral deficits in a mouse model of Alzheimer's disease. J. Neurosci. 2010, 30, 11157-11166. [CrossRef]

46. Webster, S.J.; Bachstetter, A.D.; Van Eldik, L.J. Comprehensive behavioral characterization of an APP/PS-1 double knock-in mouse model of Alzheimer's disease. Alzheimers Res. Ther. 2013, 5, 28. [CrossRef]

47. Homolak, J.; Mudrovcic, M.; Vukic, B.; Toljan, K. Circadian Rhythm and Alzheimer's Disease. Med. Sci. 2018, 6, 52. [CrossRef] [PubMed]

48. Hoyles, L.; Pontifex, M.G.; Rodriguez-Ramiro, I.; Anis-Alavi, M.A.; Jelane, K.S.; Snelling, T.; Solito, E.; Fonseca, S.; Carvalho, A.L.; Carding, S.R.; et al. Regulation of blood-brain barrier integrity by microbiome-associated methylamines and cognition by trimethylamine N-oxide. Microbiome 2021, 9, 235. [CrossRef]

49. Pontifex, M.G.; Martinsen, A.; Saleh, R.N.M.; Harden, G.; Tejera, N.; Müller, M.; Fox, C.; Vauzour, D.; Minihane, A.M. APOE4 genotype exacerbates the impact of menopause on cognition and synaptic plasticity in APOE-TR mice. FASEB J. 2021, 35, e21583. [CrossRef] [PubMed]

50. Dere, E.; Huston, J.P.; De Souza Silva, M.A. The pharmacology, neuroanatomy and neurogenetics of one-trial object recognition in rodents. Neurosci. Biobehav. Rev. 2007, 31, 673-704. [CrossRef] 